\title{
A PRODUÇÃO DO CONHECIMENTO EM SERVIÇO SOCIAL
}

\author{
Prof. Dr. Pe. Mário José Filho ${ }^{1}$
}

\section{RESUMO}

O presente artigo, a partir de reflexões sobre a produção do conhecimento em Serviço Social, aponta reflexões sobre a prática profissional que efetivamente tem contribuído para o fortalecimento da profissão, através da pesquisa. A necessidade da pesquisa não parte exclusivamente do pólo de desenvolvimento científico e tecnológico, isto é, da Universidade. Pensar o Serviço Social na contemporaneidade requer lançar olhar às novas exigências postas à profissão - eminentemente investigativa e interventiva atento a essas novas configurações, o projeto profissional encontra-se em confronto com o projeto societário vigente. Referente à produção científica do Serviço Social, optou-se pelo levantamento e análise de seus eixos temáticos, a fim de verificar sua consonância com as novas exigências da contemporaneidade, provenientes das profundas mudanças no mundo do trabalho a partir dos anos 1970 e as repercussões destas transformações, verificadas também, na esfera do Estado e em sua relação com a sociedade, bem como sua relação com as linhas de pesquisa dos Programas de Pós-Graduação. Nota-se o crescimento de trabalhos elaborados no tocante a prática profissional nos programas de pós-graduação. $\mathrm{O}$ mundo do trabalho absorve uma significativa relevância, visto em contraponto aos demais temas. De maneira mais acentuada nas ciências humanas, vivese um momento determinado como crise dos paradigmas, numa busca a referenciais teóricos que dêem conta de uma maior aproximação com a dinâmica do real, imbricados de perspectiva crítica e pluralista, com direcionamento social, atento aos valores éticohumanistas como a liberdade, a igualdade e a justiça.

PALAVRAS-CHAVE: Prática Profissional, Serviço Social, Pesquisa, Conhecimento

\footnotetext{
${ }^{1}$ Professor Adjunto da Universidade Estadual Paulista - Unesp - Campus de Franca - do Curso de Graduação em Serviço Social e do Programa de Pós-Graduação em Serviço Social, vice-coordenador da UNATI - UNESP (FRANCA), vice-coordenador do Programa de Pós-Graduação em Serviço Social, Presidente da Comissão Permanente de Pesquisa da FHDSS, líder do Grupo de Pesquisa PRAPES (Prática de Pesquisa) e do Grupo GEPEFA (Grupo de Estudos e Pesquisas Sobre Família), membro do Conselho Editorial da Revista Serviço Social \& Realidade - Unesp.
} 


\section{INTRODUÇÃO}

Falar sobre a produção do conhecimento em Serviço Social, não é tarefa fácil, principalmente tendo-se em vista a expansão dos cursos de graduação em Serviço Social e os programas de pós-graduação em Serviço Social nos últimos anos. As minhas reflexões partem da minha experiência enquanto pesquisador, apoiadas na visão bibliográfica de vários autores que discutem a questão.

Refletir sobre a questão do conhecimento no âmbito do Serviço Social, significa reconhecer que a área não nos confere por si só, um patamar seguro, um ponto de partida sólido para o necessário aprofundamento da reflexão.

É preciso buscar apoio em outras fontes como a filosofia e o conjunto de saberes a que se chama usualmente de ciências sociais. Na busca desses saberes procura-se a Universidade, que por si só deveria ser um espaço privilegiado para a construção do conhecimento; mas quero também salientar que acredito que pensar a produção do conhecimento em Serviço Social, é pensar na própria prática profissional, nem sempre vista como produtora de saberes.

A idéia de universidade como pólo de desenvolvimento científico e tecnológico constitui um paradoxo brasileiro, pois apesar de necessitar do avanço da ciência para efetivar o seu processo de modernização, no Brasil se encerra a pesquisa em caminhos cheios de atalhos e encruzilhadas que dificultam a sua expansão.

Não é difícil constatar os obstáculos impostos a organização científica, a partir dos órgãos do Ministério da Educação, como expressão de uma compreensão abstrata da universidade.

É importante lembrar que se muitos situam a pesquisa dentro dos muros universitários, na academia, não podemos deixar de relembrar que a produção científica e a sua organização, tiveram sua origem diretamente ligados a administração pública, Revista Serviço Social \& Saúde. UNICAMP Campinas, v. VII-VIII, n. 7-8, Dez. 2009 
como por exemplo: Instituto Adolpho Lutz (1893), Instituto Oswaldo Cruz (1899), Instituto Butantã (1899) e Instituto de Biologia de São Paulo (1924), que ainda hoje desenvolvem suas pesquisas; bem como outros institutos mais recentes.

O que queremos salientar é que a necessidade da pesquisa não parte exclusivamente do pólo de desenvolvimento científico e tecnológico, isto é, da Universidade.

Por volta dos anos de 1950, existe uma proliferação das universidades e muitos pesquisadores dos Institutos, buscam a Universidade como apoio e espaço possível com suporte financeiro e material indispensáveis a satisfação das suas necessidades pessoais e de produtores de conhecimento.

Se considerarmos esse tempo (1950) até os dias atuais, podemos dizer que é recente a existência de uma produção científica consistente e permanente, até mesmo no campo das "ciências básicas", na realidade brasileira.

Com o processo de "migração" dos pesquisadores dos Institutos para dentro das Universidades, podemos dizer que houve a institucionalização da pesquisa.

É nesse contexto de produção científica que germina a pós-graduação.

A primeira pós-graduação, dentro de um sistema de universidade é a USP (1932), primeira Universidade Brasileira entendida como ensino/pesquisa de extensão.

O primeiro mestrado em 1969 e em meados de 1970 começam as análises e avaliações de sistemas de pós-graduação.

Podemos dizer que nosso sistema universitário é muito jovem. Atualmente mais ou menos 330 universidades tem pró-reitoria de pós-graduação. Já foram elaborados e revistos 5 (cinco) planos nacionais de pós-graduação. 
Alguns dados gerais da Universidade Brasileira:

2000 Instituições de Ensino Superior

150 Universidades Públicas ( a maioria federais)

3 milhões de estudantes ( $9 \%$ da população entre 18 e 24 anos)

150.000 estudantes de pós-graduação

2.800 cursos de pós-graduação (mestrado e doutorado).

Neste universo de produção científica o Serviço Social se situa com programas de pós-graduação nível mestrado e programas nível doutorado no Brasil.

Como em outras áreas os PPGSS tem por finalidade "dar aos professores universitários e aos profissionais ligados às instituições de prestação de serviços uma formação viabilizadora da transmissão e da produção do conhecimento científico" (SETÚBAL, 2002, p. 80).

Podemos dizer que o Mestrado e o Doutorado procuram formar professores e profissionais pesquisadores que possam à partir das demandas sociais, produzir um saber legitimado pela academia e órgãos financiadores de projetos de pesquisa. Bonetti - Dilseia Adeodatta (1992, p. 59) diz que “os cursos de pós-graduação no país, foram criados para preparar docentes para as universidades e promover o desenvolvimento da pesquisa dentro dos parâmetros reformistas do governo" (in SETÚBAL, 2002, p. 81).

Sem dúvida alguma nos interroga uma questão que diz respeito a todos nós: “Será que nossos programas de pós-graduação estão inseridos numa perspectiva de formar professores para o $3^{\circ}$ grau?"

Respondo essa interrogação, afirmando que mesmo com todas as controvérsias e contradições que existem sobre a Universidade Brasileira, tem sido uma constante a busca de "preparar pesquisadores", ou seja, profissionais capacitados para criar e desenvolver projetos de pesquisas científicas na área social. 
Não resta dúvida de que esse objetivo é por demais desafiante para um país que não tem tradição em pesquisa. Para o Serviço Social ele nos parece duplamente inquietante: primeiramente, por ser uma prática inserida numa realidade concreta sem tradição em pesquisa, e em segundo lugar, por ter se inserido no mercado de trabalho dessa sociedade, para prestar serviços assistenciais as populações menos favorecidas pelo sistema capitalista de produção. Esses dois aspectos, elementos de um mesmo cosmo, ao se entrelaçarem no interior do Serviço Social, passam a ser determinantes e ao mesmo tempo determinados pela percepção de mundo, homem, objeto e conhecimento adotados pelo pesquisador, enfim, pela forma com que esse tipo de prática social enfrenta as questões conjunturais inibidoras do desenvolvimento do saber na área social (SETÚBAL, 2002, p. $82-3)$.

Lançando olhar sobre a trajetória profissional, é possível perceber as diferentes determinações sob as quais a prática profissional se encontrou, as diversas exigências postas a esta e as propostas advindas da própria categoria de assistentes sociais, para repensar e (re)direcionar a profissão, proporcionando espaços de reflexão no âmbito teórico, metodológico, ético, político e pedagógico e demais eixos fundantes da profissão.

Durante os anos de 1980, o país vive uma intensa crise econômica, política e social. No que tange a assistência social, há uma busca do entendimento à pobreza, percebendo-se que a sociedade civil é formada por uma classe de excluídos e incluídos.

A Constituição Brasileira de 1988, define a assistência social como um complemento da previdência social, sendo dirigida aos necessitados, sem vínculo formal com o trabalho e àqueles que não possuem renda, isto é, crianças, idosos e deficientes físicos. 
Ao mesmo passo em que é possível perceber, no decorrer dos anos, que não foi possível superar os problemas sociais através das ações governamentais, muitas vezes dotadas de caráter emergencial e pontual, negligenciando a dignidade do ser humano, sem perceber que este é um sujeito histórico e imbricado de totalidade.

De forma intensa, a partir de 1990 a sociedade brasileira passa por profundas transformações, sob os ditames do ideário neoliberal juntamente ao fortalecimento da globalização, a questão social adquire ares contemporâneos, conseqüentemente a demanda profissional do Serviço Social apresenta-se com novas configurações, daí a importância e necessidade de uma ação profissional voltada às questões postas por essa sociedade.

Pensar o Serviço Social na contemporaneidade exige lançar olhar às novas exigências postas à profissão - eminentemente investigativa e interventiva - atento a essas novas configurações, o projeto profissional encontra-se em confronto com o projeto societário vigente.

A questão social como fruto e expressão das desigualdades ocasionadas pelo modo de produção capitalista, tem como agravante, as transformações ocorridas no mundo do trabalho nas últimas décadas. O trabalhador já não encontra estabilidade no emprego, o mercado exige cada vez mais e emprega cada vez menos.

A precarização do trabalho que mantém um grande número de trabalhadores excluídos do mercado, do mesmo modo, intensifica a atuação de trabalhadores do mercado informal. Essa heterogeneidade da classe trabalhadora acaba por minar as possibilidades da formação e desenvolvimento de formas de luta e de ações combativas.

O número dos excluídos aumenta, são homens, mulheres, crianças, que vivem (sobrevivem) sob condições que ferem gravemente a dignidade humana. Pessoas que 
encontram imensas dificuldades e/ou não vêem a possibilidade de se constituir como sujeitos sociais e políticos.

As políticas sociais que deveriam atender a esta população, sofrem os golpes da proposta neoliberal, um Estado que admite os ditames do modelo neoliberal, conseqüentemente se afasta dos compromissos sociais, canalizando o fundo público para interesses privados.

Ao profissional é exigido uma certa bagagem teórico-metodológica, para que possa elaborar uma interpretação crítica do contexto ao qual faz parte. Torna-se vital para o exercício profissional dimensionar o novo e captar - e segundo Iamamoto (2001, p. 80) - "inéditas mediações históricas", ou seja, desenvolver ações diferenciadas para o enfrentamento da questão social e suas determinações.

Com compromisso e dotado de competência para tal, cabe ao assistente social decifrar e apreender as múltiplas facetas da questão social, para que torne possível projetar formas de resistência e enfrentamento, atentas a essas características.

O pesquisador tem um compromisso para e com a sociedade, o processo de conhecimento ao qual se embrenha pode e deve responder à sociedade, ou seja, o saber não deve servir como instrumento de dominação, mas como alternativa de libertação.

O modo de ser do novo intelectual não pode mais consistir na eloquiência, motor exterior e momentâneo dos afetos e das paixões, mas num imiscuir-se ativamente na vida prática, como construtor, organizador, persuasor permanente, já que não mais apenas orador puro e superior, todavia, do espírito matemático abstrato; da técnica - trabalho eleva-se a técnica-ciência e à concepção humanística - histórica, sem a qual permanece especialista e não se chega a dirigente (especialista mas político) (JORGE, 1997, p.170 apud GRAMSCI, 1979, p. 8). 
Essa confusão - referente à atribuição da prática e teoria - se não esclarecida já na formação profissional, cria espaço para uma ação profissional dotada de ecletismo ou até mesmo pautada no senso comum. As indagações e reflexões sobre a cientificidade na profissão não se referem tão somente à questão da relação teoria/prática, mas também aos paradigmas teóricos.

Atualmente, na esfera da produção de conhecimentos, estamos face ao que se denomina "crise de paradigmas" nas ciências sociais, ou mesmo, crise dos modelos analíticos, explicativos no âmbito das ciências sociais.

A chamada crise de paradigmas não é uma questão nova nas ciências sociais, o que esse debate tem de novo são as suas configurações na contemporaneidade e seu rebatimento na pesquisa no campo do Serviço Social.

Partindo deste pressuposto, a crise traz de novidade uma tendência de combate ao dogmatismo, ou seja,

[...] os diferentes modelos explicativos não estão conseguindo responder às novas configurações da realidade em transformação, colocando o desafio de se buscar novos caminhos analíticos, novas vertentes explicativas. E, em busca desse novo, $[\ldots]$ as discussões e críticas dos analistas evidenciam a convicção e impossibilidade do pesquisador fechar-se hermeticamente num único paradigma, qualquer que seja ele. (CARVALHO, 1992, p. 49)

Em termos de sua capacidade explicativa, é imprescindível que o pesquisador crie possibilidades para uma postura aberta e crítica, negando a adoção da capacidade castradora do dogmatismo, diante a proposta pluralista.

Necessário dizer que estar aberto à postura plural traz consigo o risco de cair-se no ecletismo, numa mistura indiscriminada de conceitos até mesmo contraditórios “conciliar pontos de vista inconciliáveis" (COUTINHO, 1991, p. 13) - travestidos de Revista Serviço Social \& Saúde. UNICAMP Campinas, v. VII-VIII, n. 7-8, Dez. 2009 
uma falsa coerência. Ter uma postura plural, no âmbito da pesquisa, consiste em integrar conceitos e teorias que não sejam antagônicos ou contraditórios, segundo um eixo coerente. Dessa forma o pluralismo,

[...] não é assim sinônimo de ecletismo. É sinônimo de abertura para o diferente, de respeito pela posição alheia, considerando que essa posição, ao nos advertir para os nossos erros e limites, e ao nos fornecer sugestões, é necessária ao próprio desenvolvimento da nossa posição, e de modo geral, da ciência (COUTINHO, 1991, p. 14).

Nesse sentido, em âmbito estadual, podemos dizer que a PUC-SP e a UNESPFranca tem produzido conhecimentos científicos que visualizam o Serviço Social dentro do movimento histórico do atual momento, compreendendo as inserções históricas e os diferentes posicionamentos e estratégias.

Os cursos de Pós-Graduação vêm nesse processo de consolidação, constituindose entre as diferentes áreas do saber e na perspectiva teórico-metodológica um espaço para formação de pesquisadores e docentes.

Podemos dizer que os Programas de Pós-Graduação se encontram num momento de maturação do saber, construindo questionamentos que respondam às necessidades de hoje. Penso que o compromisso da Pós-Graduação é pensar a sociedade sob a pressão neoliberal.

A partir de tudo o que já se produziu, nesse cenário de mudanças, deve-se pensar a qualidade científica da área a partir dos debates já consolidados expressos no ensinopesquisa e extensão e nos encontros da categoria.

A Pós-Graduação é necessariamente uma interlocução com a realidade e como tal deve buscar sempre "desvendar" a realidade, possibilitando ações concretas de enfrentamento. 
Temos de reconhecer sem atribuirmos aos programas de pósgraduação uma importância ímpar no processo da construção do conhecimento no Serviço Social e diminuirmos as iniciativas realizadas anteriormente e fora desse contexto, que foi a partir da criação da pós-graduação na área, principalmente após a saída dos primeiros mestres e doutores, que a pesquisa se tem apresentado de forma mais sistematizada e acentuada. De lá pra cá, apesar das dificuldades institucionais vividas pelos programas, como também pelos pesquisadores por esses formados, vemos emergir dia-a-dia novas produções de pesquisa no Serviço Social (SETÚBAL, 2002, p. 84).

\section{A) LINHAS DE PESQUISA}

As linhas de pesquisa da Pós-Graduação em Serviço Social atendem à problemática, no tocante ao mundo do trabalho, relações entre Estado e Sociedade, dos desdobramentos acerca da vida operária, a abrangência das políticas públicas e as relações com a Sociedade e com os Movimentos Sociais que são temas pertinentes, como foi possível visualizar em nossa pesquisa, mesmo porque estes temas são constituintes das linhas de pesquisa dos programas.

Cabe ressaltar, que na Pós-Graduação, a preocupação com a formação do profissional mostra-se de certa forma acentuada, a partir de abordagens acerca aos desafios existentes na constituição do processo de formação, até mesmo uma abordagem no âmbito da docência.

É possível identificar, na Pós-Graduação, a presença de inquietações acerca ao novo agir profissional, frente às necessidades da realidade social. 


\section{B) TENDÊNCIAS TEMÁTICAS: ASPECTOS RELEVANTES}

Referente à produção científica do Serviço Social, optou-se pelo levantamento e análise de seus eixos temáticos, a fim de verificar sua consonância com as novas exigências da contemporaneidade, provenientes das profundas mudanças no mundo do trabalho a partir dos anos 1970 e as repercussões destas transformações, verificadas também, na esfera do Estado e em sua relação com a sociedade, bem como sua relação com as linhas de pesquisa dos Programas de Pós-Graduação.

Conforme Iamamoto (2001, p. 167), alguns temas são relevantes ao debate contemporâneo, pois se constituem elementos importantes para a apreensão dos processos determinantes da vida social, especificamente no âmbito da questão social. Temas estes a saber: o mundo do trabalho, relações entre Estado e Sociedade Civil, Movimentos Sociais, Políticas Sociais, Seguridade e Assistência Social.

O Assistente Social, diante as determinações da atualidade, assume o perfil de um profissional comprometido com os valores democráticos, incessante na luta pela efetivação da cidadania e dignidade da vida humana.

[...] para que a categoria profissional se arme de elementos teóricos e de informações da realidade capazes de subsidiá-la na formulação de propostas profissionais, isto é, na construção de programáticas de trabalho, tanto no campo da formulação de políticas sociais como de sua implementação (IAMAMOTO, 2001, p. 169).

Todas essas transformações na vida social, ocasionada principalmente pelas mudanças no mundo do trabalho - a precarização deste e consequiente fragmentação da dignidade da vida humana - o mercado tomado como eixo regulador das relações, junto ao aparato ideológico neoliberalista - conservador e privatista, trilha caminho para a redução das funções públicas a favor da privatização - enfim, vive-se num contexto que 
fere profundamente os valores democráticos e prejudica qualquer possibilidade de concretização do exercício da cidadania.

A efetivação da ação profissional atenta a essa realidade não é restrita somente ao momento de atuação dos profissionais, mas, essas questões devem permear a formação para o exercício da carreira, e através da pesquisa surge a possibilidade para a superação da dicotomia entre teoria e prática, capaz de proporcionar recursos para a apreensão dos processos da vida social que permita vislumbrar possibilidades de interferência nesses processos.

Acerca os dados levantados, nota-se o crescimento de trabalhos elaborados no tocante a prática profissional, item que aqui abrange questões relacionadas à ética, compromisso, transformação da realidade, análises sobre a realidade social, enfim, propostas e desafios à prática profissional

O mundo do trabalho absorve uma significativa relevância, visto em contraponto aos demais temas. Questões relativas a configurações do mundo do trabalho, a precarização deste, e suas repercussões como a exploração da força de trabalho, no meio urbano e rural - tanto do adulto, homem e mulher, quanto da criança e do adolescente e o crescimento do trabalho informal e todas as restrições ao trabalhador que este envolve.

Sob os ditames ideológicos do neoliberalismo, as relações entre Estado e a sociedade são constantemente prejudicadas, visto que o do Estado diante as políticas públicas em favor da regulação do mercado e sua exigência que crescente privatização dos serviços públicos. Dessa forma a população sofre significativas perdas no tocante dos direitos sociais, diante políticas muitas vezes castradoras e restritas, que não atendem aos valores democráticos e a crescente demanda. Tema este pertinente nos 
quatro anos analisados, mantendo uma certa predominância diante as demais problemáticas.

As relações estabelecidas na vida social absorvem uma atenção relevante, a família, a saúde, o idoso, as relações de gênero, questões acerca da criança e do adolescente, adquirem novas nuances na contemporaneidade. Constituindo a demanda profissional, a vivência de tais sujeitos envolve certa complexidade, própria da realidade e conjuntura a qual faz parte, sendo assim, pertinente ao profissional identificar os processos que envolvem a vida social desses sujeitos.

De maneira mais acentuada nas ciências humanas, vive-se um momento determinado como crise dos paradigmas, numa busca a referenciais teóricos que dêem conta de uma maior aproximação com a dinâmica do real, imbricados de perspectiva crítica e pluralista, com direcionamento social, atento aos valores ético-humanistas como a liberdade, a igualdade e a justiça.

Destacamos também a importância da contribuição do conhecimento científico do Serviço Social brasileiro, num intercâmbio com outras instituições internacionais.

\section{CONSIDERAÇÕES FINAIS}

Pretendemos com o presente estudo, trazer algumas contribuições à reflexão sobre aspectos da formação profissional do assistente social, especificamente, ao que remete à relação entre o processo de formação profissional e a atividade investigativa, através da pesquisa.

As reflexões arroladas a partir da caracterização e função da universidade, em especial a brasileira, permitiram aproximar o olhar às suas determinações. Podemos dizer que a universidade como uma instituição ainda imbricada de determinações elitistas e excludentes, muitas de suas ações são determinadas pela ideologia neoliberal, 
a fim de atender às especificações do mercado. Daí a necessidade de revisão de seu papel na sociedade, pois a universidade tem capacidade de constituir-se espaço democrático que sirva à transformação dessa mesma sociedade.

A análise dos dados referentes à produção científica nos dois Programas de PósGraduação em Serviço Social, particularmente a partir do levantamento de seus eixos temáticos, possibilitou visualizarmos - tanto na graduação, quanto na pós-graduação - a relevância dada às temáticas que imprimem reflexões no tocante ao mundo do trabalho, questões relativas a sua configuração e precarização, visto as constantes transformações na contemporaneidade.

Possível perceber um considerável aumento das indagações, particularmente referentes à prática profissional, o que de certa forma demonstra o crescente interesse do Pós-Graduado em imprimir caráter científico, acerca do momento do agir profissional.

Podemos identificar preocupações acerca ao novo agir profissional, questões relacionadas à ética, compromisso profissional, desafios e propostas colocadas ao cotidiano profissional, e sobre os desafios na reflexão dos procedimentos teóricos e metodológicos da profissão.

Para a apreensão do complexo movimento do real a pesquisa mostra-se atividade primordial e conseqüentemente é capaz de possibilitar a construção de novos saberes e novas formas de enfrentamento das constantes diversidades, cabe aqui, que seja pautada sobre consistentes fundamentos teórico-metodológicos, pronta a responder às reais necessidades da demanda profissional.

O profissional deve pensar a sua prática e seus veios com a teoria, de modo que consiga visualizar propostas de ação fundamentadas e coerentes, superando a dicotomia entre teoria e prática vista por muitos profissionais, e mais, apreender e analisar dados dessa realidade, mergulhar-se num processo reflexivo e altamente criativo, em busca de 
aprofundar-se na dinâmica dos processos determinantes da vida humana, de forma que possibilite direcionar a ação profissional em consonância às novas necessidades do sujeito social.

Significa superar a prática pela prática, no sentido de avançar na concretização e garantia da vivência digna do homem.

Assim avançar em meio ao momento determinado pela crise de paradigmas nas ciências sociais aplicadas, significa buscar referenciais teóricos e metodológicos capazes de viabilizar uma apreensão mais clara da complexidade do real, capaz de fornecer subsídios para o desvendamento de algumas configurações dos processos do cotidiano.

Perceber algumas lacunas deixadas ainda no processo de formação profissional e buscar possibilidades que avancem nesse sentido, significa trilhar caminho à efetivação de um agir profissional atento aos anseios da demanda, atento ao projeto de um fazer profissional com o compromisso da ética, da democracia e da justiça.

Enfim, cabe ressaltar que não pretendemos fechar a possibilidade de surgirem outras reflexões sobre a temática proposta, visto que, se constituiu numa discussão sobre a pesquisa na universidade, não fornecendo respostas definitivas e fechadas.

Lembramos aqui que a observância, a apreensão e o desvelamento do real configuram um processo de sucessivas aproximações entre o saber e o pesquisar.

Apontamos para a necessidade da expansão das discussões no tocante à temática - produção científica no Serviço Social e suas configurações - no sentido de buscar consonância entre a direção proposta à profissão e as reais configurações do espaço de atuação profissional, ou seja, atentar às novas necessidades e inquietações surgidas em meio o real. 


\begin{abstract}
Based on some reflections on Social Work knowledge production, this article indicates the reflections on professional practice which have effectively contributed for the profession strengthening, by means of research. The need of research does not come exclusively from the pole of scientifical and technological development, that is, the University. To think the contemporariness of the Social Work, requires a look at the new demands posed to the profession - highly investigative and interventionist attentive to these new configurations, the professional process conflicts with the current societarian project. Relative to the Social Work scientific production, the option has been the research and analysis of the axis of its themes, in order to verify the consistency with the new contemporariness demands, coming from the deep changes in the working world since 1970 and the repercussion of these transformations, also verified at the state sphere and at its relationship with society as well as with the relation with Postgraduating Programs research lines. We notice the elaborated works growth regarding the professional practice in postgraduating programs. The working world absorbs a significantly relevance, as a counterpoint to the other themes. More prominently in the human sciences, we live a determinate moment as paradigms crisis, searching theoretical references which will accomplish a greater approximation with the dynamics of real overlapped of critical and pluralist perspectives targeted to social, attemptable to the ethical-humanitarian values as liberty, equality and justice.
\end{abstract}

KEYWORDS: Professional Practice, Social Work, Research, Knowledge

\title{
REFERÊNCIAS BIBLIOGRÁFICAS
}

ABESS. A produção do conhecimento e o Serviço Social. Cadernos ABESS, n. 5, maio 1995.

Produção científica e formação profissional. Cadernos ABESS, n. 6, fev. 1998.

Formação profissional: trajetórias e desafios. Cadernos ABESS. n. 7, nov. 1997. Edição especial. 
.: Diretrizes curriculares e pesquisa em Serviço Social. Cadernos ABESS, n. 8, nov. 1998.

ABEPSS. Reforma do ensino superior e Serviço Social. Temporalis, ano 1, n. 1, jan./jun. 2000.

Diretrizes curriculares: polêmicas e perspectivas. Temporalis, ano 1, n. 2, jul./dez. 2000.

Fórum nacional sobre avaliação institucional dos cursos de Serviço Social: textos e documentos. Temporalis, ano 2, out. 2001. Suplemento.

Relatório da Oficina Nacional: o ensino do trabalho do assistente social.

Temporalis, ano 3, nov. 2002. Suplemento.

ANDERSON, P. Balanço do neoliberalismo. In: SADER, E.; BORÓN, A. (Org.). Pósneoliberalismo: as políticas sociais e o estado democrático. São Paulo: Paz e Terra, 1996.

BRASIL, M. G. M. Reflexão sobre a pesquisa qualitativa em Serviço Social. Serviço Social \& Realidade, Franca, v. 4, n. 1, p. 7-9, 1995.

BRITES, C. M.; BARROCO, M. L. S. A centralidade ética na formação profissional. Diretrizes curriculares: polêmicas e perspectivas. Temporalis, ano 1, n. 2, p. 19-33, jul./dez. 2000.

CALAZANS, J. (Org.). Iniciação científica: construindo o pensamento crítico. 2. ed. São Paulo: Cortez, 2002.

CARVALHO, A.M.P.de. O projeto da formação profissional do assistente social na conjuntura brasileira. Cadernos ABESS: o processo da formação profissional do assistente social, São Paulo, n. 1, p. 17-42, out. 1986.

A pesquisa no debate contemporâneo e o Serviço Social. Cadernos ABESS: a

produção do conhecimento e o Serviço Social, São Paulo, n. 5, p. 43- 66, maio 1992. 
CHAUÍ, M. Escritos sobre a universidade. São Paulo: UNESP, 2001.

CHIZZOTTI, A. Prolegômenos à pesquisa. In: __. Pesquisar em Ciências Humanas e Sociais. 2. ed. São Paulo: Cortez, 1998. p. 11-21.

COUTINHO, C. N. Pluralismo: dimensões teóricas e políticas. Cadernos ABESS: Ensino em Serviço Social: pluralismo e formação profissional, n. 4, p. 5-17, maio 1991. DEMO, P. Pesquisa: princípio científico e educativo. 9. ed. São Paulo: Cortez, 2002. IAMAMOTO, M. V. Reforma do ensino superior e Serviço Social. Temporalis: revista da ABEPSS, ano 1, n. 1, p. 35-79, jan./jun. 2000.

. O Serviço Social na contemporaneidade: trabalho e formação profissional. 4. ed. São Paulo: Cortez, 2001.

IANNI, O. A história da mundialização. In: A sociedade global. 4. ed. Rio de Janeiro: Civilização Brasileira, 1996. cap. 3.

JORGE, M. R. T. A pesquisa qualitativa: premissas, possibilidades e posturas. Serviço Social \& Realidade, v. 6, n. 2, p. 159-171, 1997.

LEHFELD, N. A. S. A iniciação científica e sua importância para a formação profissional. Serviço Social \& Realidade, v. 4, n. 1, p. 43-52, 1995.

MARTINS, L. C. O. O programa de pós-graduação em Serviço Social da UNESP, campus Franca: uma análise das tendências temáticas das dissertações de mestrado. Franca, 2001. (Tese apresentada em concurso público da Faculdade de História, Direito e Serviço Social, UNESP, para obtenção do título de livre docente em Serviço Social). MINAYO, M. C. S. (Org.). Pesquisa social: teoria, método e criatividade. 11. ed. Petrópolis: Vozes, 1999. 